\title{
Adding Silanes to MMA : The Effects on the Water Absorption, Adhesive Strength and Mechanical Properties of Acrylic Denture Base Resins
}

\author{
Takahito KANIE, Koichi FUJII, Hiroyuki ARIKAWA and Katsuichiro INOUE \\ Department of Biomaterials Science, Kagoshima University Dental School \\ 8-35-1 Sakuragaoka, Kagoshima 890-8544, Japan
}

Received June 13, 2000 /Accepted September 19, 2000

\begin{abstract}
The adhesive strength of porcelain artificial teeth and polymethylmethacrylates (PMMAs), which contained silanes with various number of vinyl or ethoxy groups, and the mechanical and physical properties of the PMMAs were measured. Four types of PMMAs with silanes showed high adhesive shear strength and caused fractures in the porcelain. Water absorption of the PMMAs increased with the addition of silane, but that of one type with silane was almost the same as the PMMA only type. The flexural strengths of the PMMAs with silane, except for one type, showed no significant differences compared with that of PMMA $(p<0.05)$. The Tg levels of all PMMAs with silane fell less than that of PMMA. From these results, it was found that PMMA with silane from three vinyl groups and one ethoxy group showed excellent chemical bonding to porcelain and low water absorption.
\end{abstract}

Key words: Silane, Denture base resin, Adhesive strength

\section{INTRODUCTION}

Porcelain artificial teeth generally have anchor pins planted securely into resin, because acrylic resins hardly bond to porcelain. If the chemical bond between acrylic resin and porcelain is strong, the denture base resin can steady the porcelain teeth, while infiltration of saliva or drink into the interface of the porcelain teeth and the resin will be preventable. A variety of silane is commonly used in dentistry as a composite resin coupling agent. In the conventional process, a glass filler surface is pretreated with silane solution, and the base monomer with the glass filler in the composite resin are polymerized using an initiator, which uses chemical or visible light. Furthermore, previous investigations ${ }^{1-5}$ suggested the chemical bond between an acrylic denture base resin and a porcelain tooth pretreated with a silane-coupling agent. If the surface treatment of a porcelain tooth and the polymerization of an acrylic denture base resin carried were done at the same time, the handling procedure would be simplified. On the other hand, Iwamoto ${ }^{6)}$ showed that porcelain teeth bonded tightly to the denture base resin, although the amount of water absorption within the resin increased only slightly, by adding $\gamma$-methacryloxypropyltrimethoxysilane $(\gamma$-MPTMS $)$ to a monomer of an acrylic denture base resin, and polymerized by an ordinary heating-process. Furthermore, some investigations ${ }^{7,8}$ showed that silanes adhered excellently to inorganic fillers by introducing a vinyl group, and that 
vinyltriethoxysilane increased the water-resisting qualities of composite resins.

Therefore, the water absorption, adhesive strength and mechanical properties of six acrylic denture base resins, which contained silanes with various number of ethoxy or vinyl groups, were discussed in this study.

\section{MATERIALS AND METHODS}

\section{Preparation of specimens}

The methylmethacrylate (MMA) monomer, polymethylmethacrylate (PMMA) powder and silanes used in this investigation are shown in Tables 1 and 2 together with codes, liquid-to-powder ratios and chemical formulas. The silane was added to MMA in $6 \mathrm{~mol} \%$, which was decided from a pilot study of water absorption and an adhesive test using $\gamma$-MPTMS, and 0.5 wt\% benzoylperoxide (Wako pure chemical, Osaka, Japan) was added to MMA as the initiator. Dough (a mixture of liquid and powder) was put into a Teflon mold and pressed at $2 \mathrm{MPa}$. The mold was heated at $70^{\circ} \mathrm{C}$ for $1 \mathrm{hr}$ and subsequently at $100^{\circ} \mathrm{C}$ for $1 \mathrm{hr}$ in $\mathrm{N}_{2}$ gas. A test specimen $(4 \times 3$ $\times 40 \mathrm{~mm})$ was cut from a cured PMMA sheet $(40 \times 3 \times 80 \mathrm{~mm})$ using a diamond blade (SD140, Maruto, Tokyo, Japan) and polished with emery paper (\#600).

After heat curing, the test specimens were taken out from the mold and heated again at $110^{\circ} \mathrm{C}$ for $5 \mathrm{hrs}$ to remove any residual stresses ${ }^{9,10)}$. Thereafter, the test

Table 1 Materials used in this investigation

\begin{tabular}{|c|c|c|c|c|c|}
\hline \multirow{2}{*}{ Code } & \multicolumn{2}{|r|}{ Liquid } & \multirow{2}{*}{ Powder } & \multirow{2}{*}{$\begin{array}{c}\text { Monomer/Silane } \\
(\mathrm{mol} \%)\end{array}$} & \multirow{2}{*}{$\begin{array}{l}\text { Liquid-to-powder } \\
\text { ratio }(\mathrm{g} / \mathrm{g})\end{array}$} \\
\hline & Monomer & Silane & & & \\
\hline PM & $\mathrm{MMA}^{\mathrm{a}}$ & - & $\mathrm{PMMA}^{\mathrm{h}}$ & - & \\
\hline $\mathrm{VE}$ & MMA & Vinyldimethylethoxysilane ${ }^{b}$ & PMMA & $94 / 6$ & \\
\hline VD & MMA & Vinylmethyldiethoxysilane ${ }^{c}$ & PMMA & $94 / 6$ & \\
\hline VT & MMA & Vinyltriethoxysilane ${ }^{\mathrm{d}}$ & PMMA & $94 / 6$ & $2.3 / 1$ \\
\hline DD & MMA & Divinyldiethoxysilane $e^{e}$ & PMMA & $94 / 6$ & \\
\hline $\mathrm{TE}$ & MMA & Trivinylethoxysilane $^{f}$ & PMMA & $94 / 6$ & \\
\hline MT & MMA & $\gamma$-Methacryloxypropyltrimethoxysilane $\mathrm{g}^{\mathrm{g}}$ & PMMA & $94 / 6$ & \\
\hline
\end{tabular}

${ }^{a}$ Wako Pure Chemical, Japan (Lot/ACM4069), ' Chisso, Japan (Lot/1880801), 'Gelest, USA (lot/ 95C-0595), 'Shinetsu Chemical, Japan (Lot/902021), ' Shinetsu Chemical, Japan (Lot/705013), ${ }^{\mathrm{f}}$ Gelest, USA (Lot/961-3170), ${ }^{\mathrm{g}}$ Shinetsu Chemical, Japan (Lot/VR035384), ${ }^{\mathrm{h}} \mathrm{M}-4005$, Negami Kogyo, Japan (Lot/606191, Average particle diameter: $0.10 \mathrm{~mm}$, average molecular weight: 310000)

Table 2 Chemical formula of silanes used in this investigation

\begin{tabular}{cl}
\hline Code & \multicolumn{1}{c}{ Chemical formula } \\
\hline VE & $\mathrm{CH}_{2}=\mathrm{CH}-\mathrm{Si}\left(\mathrm{OC}_{2} \mathrm{H}_{5}\right)-\left(\mathrm{CH}_{3}\right)_{2}$ \\
VD & $\mathrm{CH}_{2}=\mathrm{CH}-\mathrm{Si}\left(\mathrm{OC}_{2} \mathrm{H}_{5}\right)_{2}-\mathrm{CH}_{3}$ \\
VT & $\mathrm{CH}_{2}=\mathrm{CH}-\mathrm{Si}\left(\mathrm{OC}_{2} \mathrm{H}_{5}\right)_{3}$ \\
DD & $\left(\mathrm{CH}_{2}=\mathrm{CH}\right)_{2}-\mathrm{Si}_{2}\left(\mathrm{OC}_{2} \mathrm{H}_{5}\right)_{2}$ \\
TE & $\left(\mathrm{CH}_{2}=\mathrm{CH}\right)_{3}-\mathrm{Si}-\mathrm{OC}_{2} \mathrm{H}_{5}$ \\
MT & $\mathrm{CH}_{2}=\mathrm{C}\left(\mathrm{CH}_{3}\right)-\mathrm{COO}-\left(\mathrm{CH}_{2}\right)_{3}-\mathrm{Si}\left(\mathrm{OCH}_{3}\right)_{3}$ \\
\hline
\end{tabular}


specimens were stored in water at $37 \pm 0.5^{\circ} \mathrm{C}$ for 28 days.

\section{Water absorption}

The weights $(\mathrm{Ms})$ of test specimens $(4 \times 3 \times 20 \mathrm{~mm})$, which were cut from the cured PMMA sheet and polished, 30 min after the end of heat curing were measured with an electron balance (ER-182A, A\&D, Tokyo, Japan). The test specimens were stored in water at $37 \pm 0.5^{\circ} \mathrm{C}$ for 28 days and the weight $(\mathrm{Mx})$ was again measured. The water absorption (Ws) was calculated from the following formula:

$$
\mathrm{Ws}=(\mathrm{Mx}-\mathrm{Ms}) / \mathrm{A}
$$

where $\mathrm{A}$ is the surface area of the test specimen.

\section{Adhesive test}

A schematic representation of a test specimen for the adhesive test is shown in Fig. 1. Porcelain teeth (Ace anterior, 8-514-11, Shofu, Kyoto, Japan) were put in a Teflon mold with a rectangular parallelepiped cavity and then a self-curing acrylic resin was poured into the cavity. After a resin block was taken out from the mold, the surface of the porcelain tooth was polished to create a flat surface with emery paper (\#600). A Teflon mold with holes $(5 \phi \times 2 \mathrm{~mm})$ was put on the flat surface of the porcelain tooth and then filled with dough. After being pressed at $2 \mathrm{MPa}$, the dough was heated under the same curing conditions as described above.

The shear adhesive strength was measured with a universal testing machine (TG$50 \mathrm{kN}$, Minebea, Nagano, Japan) with a crosshead speed of $0.5 \mathrm{~mm} / \mathrm{min}$.

\section{Flexural test}

In order to measure the flexural strength and flexural moduli of the specimens

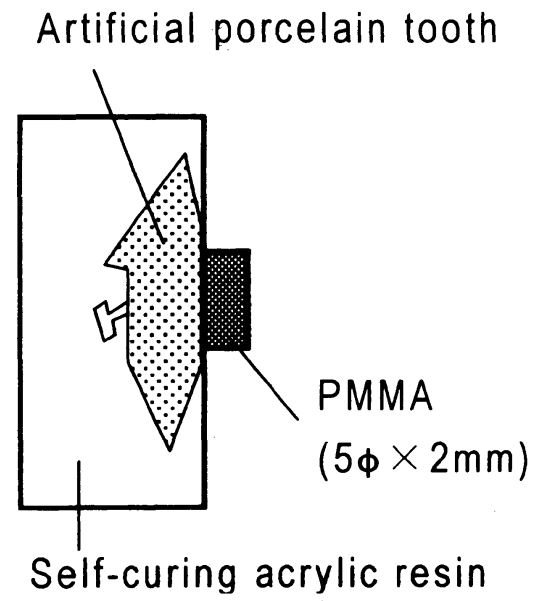

Fig. 1 Schematic representation of a test specimen used in the adhesive test. 
$(4 \times 3 \times 40 \mathrm{~mm})$, a three-point flexural test was carried out with a universal testing machine using a crosshead speed of $2 \mathrm{~mm} / \mathrm{min}$ and a span length of $20 \mathrm{~mm}$. The flexural modulus was calculated using the deflection corresponding to a load $4.9 \mathrm{~N}$ of within a proportional limit.

\section{Residual monomer}

Dry specimens $(0.1 \mathrm{~g})$ were dissolved in tetrahydrofuran (THF, $5 \mathrm{ml}$ ) at a room temperature for 2 days. The measurement of the residual monomer was done using high performance liquid chromatography (LC-5A/SPD-2A, Shimadzu, Kyoto, Japan) with a steel column (KF802, Shodex, Tokyo, Japan) maintained at $37 \pm 0.5^{\circ} \mathrm{C}$ during detection. The mobile phase was THF and the flow rate was $1 \mathrm{ml} / \mathrm{min}$. The detector wavelength and sampling solution were $254 \mathrm{~nm}$ (UV) and $25 \mu 1$, respectively. The residual monomer (\%) was calculated from the ratio of the area under the curve at peak MMA obtained before and after polymerization. The measurements were repeated three times and averaged.

\section{Relaxation modulus}

The apparatus used was a stress relaxation testing machine (Thrive Seiko,

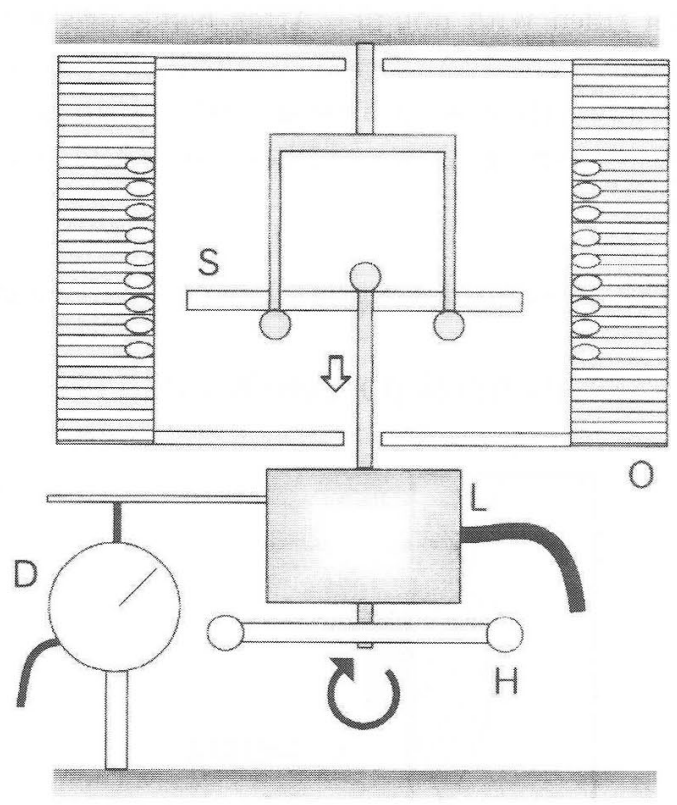

Fig. 2 Schematic representation of the apparatus used in the measurement of the relaxation modulus at temperatures from 30 to $130^{\circ} \mathrm{C}$.

D: Dial gauge, H: Handle, I: Load cell, O: Oil bath, S: Specimen 
Kagoshima, Japan), specially designed to investigate the relaxation modulus in flexural moduli, as shown in Fig. 2. The specimen $(\mathrm{S})$ is pulled downward by rotating the handle connected to the fulcrum and load cell $(H)$. The change in load is measured with a load cell and the displacement is measured with a dial gauge.

Stress relaxation was measured in air over a temperature range from 20 to 130 ${ }^{\circ} \mathrm{C}$ at a heating rate of $0.5^{\circ} \mathrm{C} / \mathrm{min}$. The span length was $14.98 \mathrm{~mm}$ and the applied flexural strain was within proportional limits less than $0.4 \%$. A relaxation modulus $\{\operatorname{Er}(2)\} 2$ sec after the start of stress was calculated from the relaxation curves.

\section{Statistical analysis}

The flexural strength and flexural modulus data, adhesive strength and water absorption were statistically analyzed with a one-way ANOVA and a Scheffe's test.

\section{RESULTS AND DISCUSSION}

The materials (VE, VD, VT, DD and MT), except for TE, showed a higher water absorption compared with that of PM, as shown in Fig. $3(\mathrm{p}<0.05)$. In spite of silane addition, the water absorption of TE was almost equal to that of PM. VT was the only material with three ethoxy groups in its molecular structure among the tested materials. Three ethoxy groups may increase water absorption. Furthermore, the water absorption of MT, which has three methoxy groups, was larger than that of VT. It was conclusive whether the difference in water absorption between VT and MT was caused by the difference in the ethoxy and methoxy groups.

Fig. 4 shows the adhesive strengths. VT, DD, TE and MT showed high adhesive

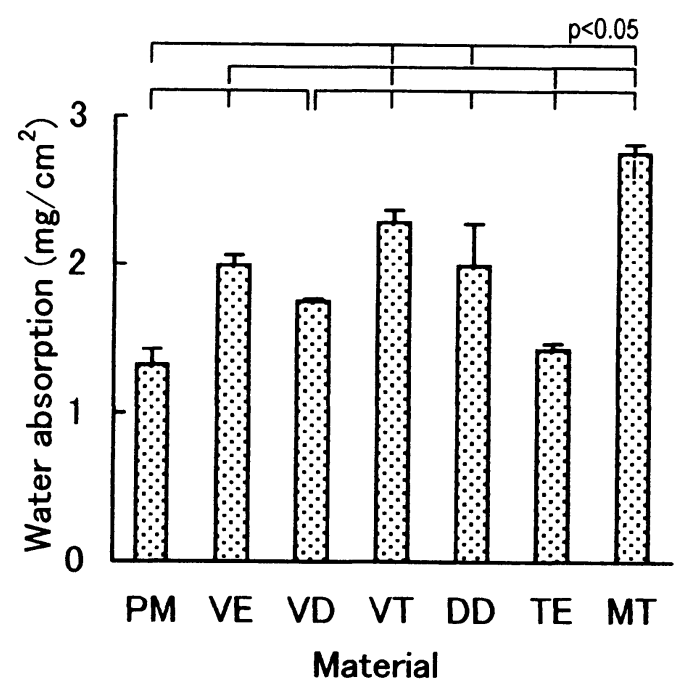

Fig. 3 Water absorption of PMMA with or without silane.

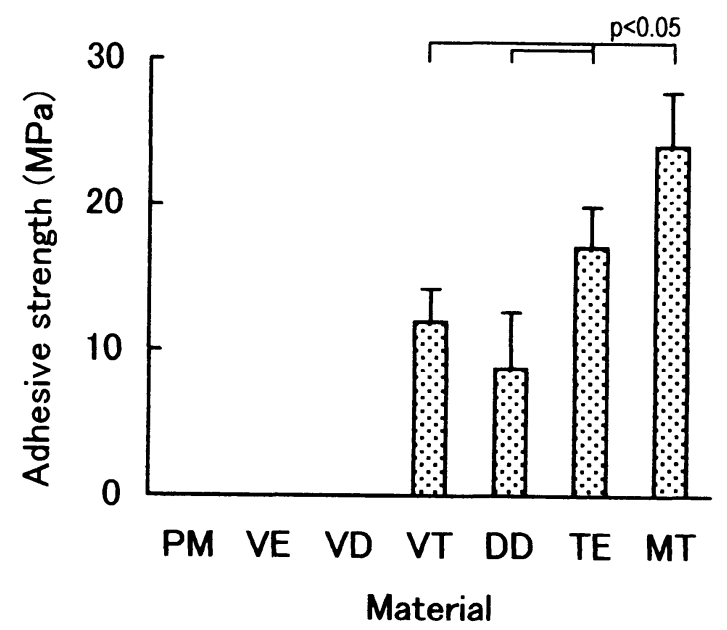

Fig. 4 Adhesive strength between porcelainartificial tooth and PMMA with or without silane. 
strength and caused failures in the porcelain. In general, it is difficult to make a single or uniform layer of silane on a porcelain tooth pretreated with silane and then polymerized with resin. However, with this experimental method, an extremely thin layer of silane was formed between the porcelain and resin because silane molecules act directly on the porcelain tooth. There was, however, no correlation between the ethoxy group number and the adhesive strength in shear, although VT, DD and TE had different adhesive strengths in spite of their cohesive failure in the porcelain tooth. If a steady adhesion bond at the interface between the porcelain and silane is formed, residual stress is generated by polymerization shrinkage on the porcelain tooth. Furthermore, if the compressive strength of the resin is small, deformation of the porcelain tooth is introduced with the resin deformation. There results could be explained by the contractive force due to the polymerization and/or of the compressive strength of the resin.

It is possible that $\mathrm{DD}$ and $\mathrm{TE}$ have a crosslinking structure with the methacrylate group of MMA because they have two or three $\mathrm{C}=\mathrm{C}$ bonds in their molecules, although no increase in their mechanical properties was observed in the flexural test. The reason is as follows: As DD, TE and MT were soaked in THF to measure the residual monomer, they swelled and did not dissolve completely. MT has one $\mathrm{C}=\mathrm{C}$ bond in the molecule. Therefore, it is satisfactory as a crosslinking structure to compose by intermolecular bonding of the methoxy group. On the other hand, the crosslinking structure of DD and TE are caused by intermolecular bond of the ethoxy group or $\mathrm{C}=\mathrm{C}$ bond in the molecule. However, a clear evidence for this idea could not be obtained from this investigation. It is thought that materials, which form three-dimensional structures via ethoxy groups during polymerization, react with $\mathrm{SiO}_{2}$, and then the adhesive strength between the porcelain tooth and PMMA effectively increase.

Tanioka et al. ${ }^{11)}$ mentioned that the number of functional silicone groups is important because the number of functional groups is linked to the formation of the adsorbed layer. In this investigation, the numbers of ethoxy groups in the bond to -Si-O- were one in V'T and TE, two in VD and DD, and three in VT. The adhesive strength of VE and TE or VD and DD, which have same number of ethoxy groups, differed from each other. VE and VD showed no adhesion and had a hydrophobic methyl group in the molecule. The hydrophobic group probably inhibits wettability; therefore the adhesive strength decreased. This is in agreement with the result of Kurata et $a l .{ }^{8)}$. Furthermore, Kurata et al. ${ }^{12)}$ reported that silane, which has three or more hydrolytic groups, is effective in increasing water resistance and sufficient surface treatment, but the substitution of a hydrolytic group with a hydrophobic group bonded to $\mathrm{Si}$ decreases the treatment effect. In this investigation, TE, which has three hydrolytic ethoxy groups, showed high adhesive strength and improved water absorption.

Figs. 5 and 6 show flexural strength and flexural modulus, respectively. The flexural strength of VT decreased markedly. In VT, the amount of residual monomer, which acts as the plasticizer, was smaller than that of the other materials, 
while the water absorption increased (Figs. 5 and 7). However, the flexural strength of VT was smaller than that of MT, which showed high water absorption. This factor does not indicate that the mechanical properties were largely decreased only by the water absorption. Nishiyama ${ }^{13)}$ reported that the amount of absorption of silane against colloidal silica increased with increasing numbers of ethoxy groups bonded to a silicone functional group. Therefore, the crosslinking layer in three-dimensions is flexible and internal stress is easily relaxed. VT, which has three ethoxy groups, in-

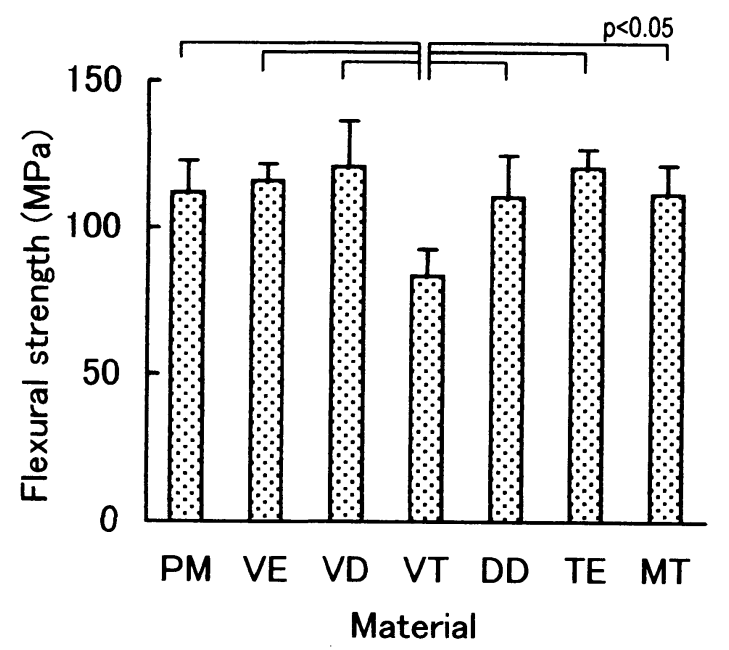

Fig. 5 Flexural strength of PMMA with or without silane.

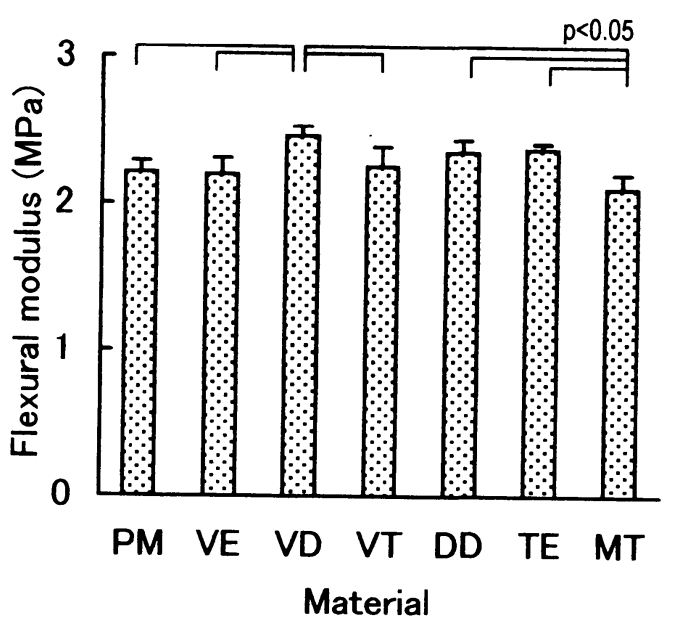

Fig. 6 Flexural modulus of PMMA with or without silane.

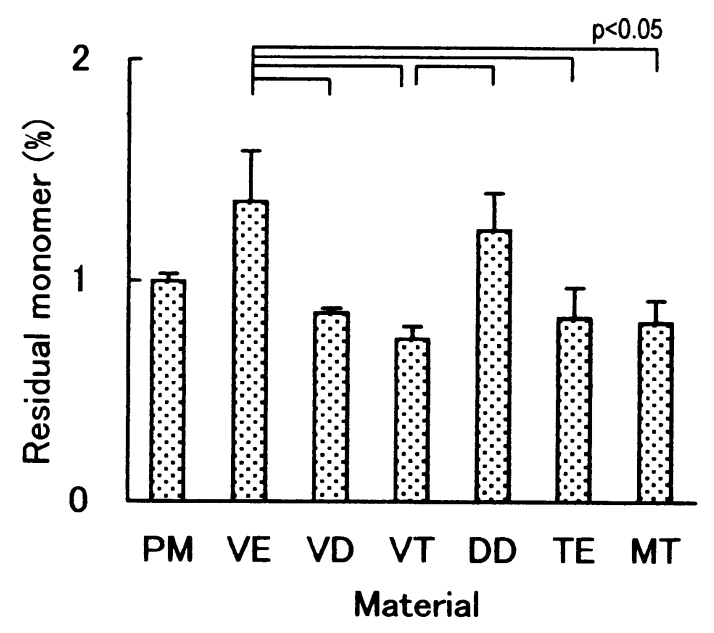

Fig. 7 Residual MMA monomer of PMMA with or without silane dissolved in THF. 
creases the flexible layer, and probably results in the decrease in strength. This confirms that the addition of VT to MMA does not obtained desirable results, because increasing the ethoxy group increases the water absorption and decreases the mechanical properties. Sakanashi et al. ${ }^{14)}$ reported results on the change in the mechanical properties with varying silane chain lengths, which has a long chain, increase the flexibility of the molecule and the internal strain is relaxed. The flexibility of the molecule effectively acts at the adhesive interface between -Si-O- and the methoxy or ethoxy groups as a result of stress relaxation. However, as the flexible layer dissipates in the polymer matrix, the mechanical properties of the polymer possibly decrease due to the flexibility. In this study, the flexural modulus of PMMA decreased with the addition of $\gamma$-MPTMS. However, the flexural modulus of materials with silane added, that had shorter chains than $\gamma$-MPTMS, did not decrease compared with that of MT. If the chain length of the molecules directly affects the flexibility at the adhesive interface, the low flexibility of the silanes used in this investigation can probably explain the lower adhesive strength of VT, DD and TE than that of MT.

The dependence of $\{\operatorname{Er}(2)\}$ on temperature is shown in Figs. 8 and 9. Glass transition temperatures $(\mathrm{Tg})$ for all materials, with added silane, decreased with the addition of silane. The fall in $\mathrm{Tg}$ with $\mathrm{VD}$ and $\mathrm{DD}$ was about $10^{\circ} \mathrm{C}$ compared with that of PM, whereas those of VE, VT and TE decreased only slightly. This fact shows that the materials will be easily transformed compared with PM, by strain at high temperature. As for $\mathrm{VD}$ and $\mathrm{DD}$, which showed relatively large decreases in $\mathrm{Tg}, \mathrm{DD}$ had much more residual monomer compared with VD. The fall in $\mathrm{Tg}$ is not necessarily independent of the amount of residual monomer, because the amount of residual monomer measured the MMA monomer in this investigation.

The purpose of this study was to find a PMMA with silane that bonded chemically to porcelain and showed less water absorption compared with MT. It is necessary to conduct further studies on the physical and chemical properties using polymers with various concentrations of silanes, which had good adhesiveness in the tested materials.

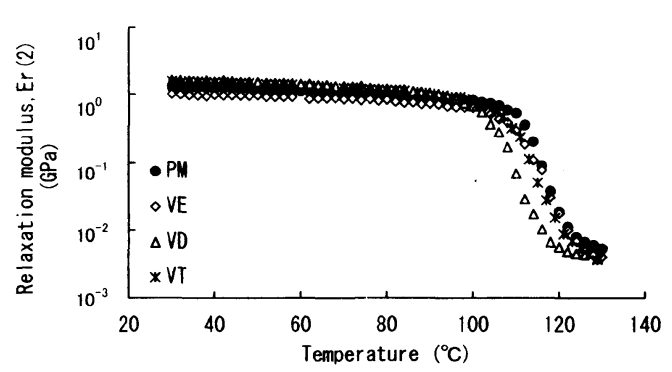

Fig. 8 Variations in the relaxation modulus at temperatures from 30 to $130^{\circ} \mathrm{C}$ for PM, VE, VD and VT.

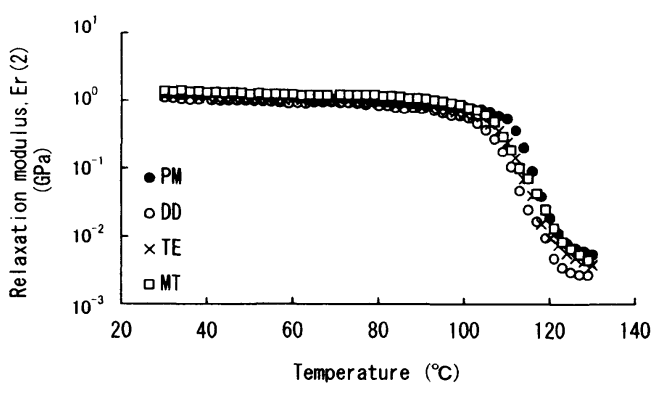

Fig. 9 Variations in the relaxation modulus at temperature from 30 to $130^{\circ} \mathrm{C}$ for $\mathrm{PM}, \mathrm{DD}, \mathrm{TE}$ and $\mathrm{MT}$. 


\section{REFERENCES}

1) Paffenbarger, G. C., Sweeny, W. T. and Bowen, R. L: Bonding porcelain teeth to acrylic resin denture bases, J Am Dent Assoc $74:$ 1018-1023, 1967.

2) Semmelman, J. O. and Kulp, P. R.: Silane bonding porcelain teeth to acrylic, J Am Dent Assoc 76:69-73, 1968 .

3) Nishiyama, M., Harada, T., Yoshihara, K., Sakuraoka, U., Ishikawa, S., Imamura, K. and Sato, T.: Study on bonding effect between methacrylate resin and silane treated porcelain, Nihon Univ Dent $J 43: 520-524,1969$. (in Japanese)

4) Marchack, B. W., Yu, Z., Zao, X.Y. and White, S. N.: Adhesion of denture tooth porcelain to heat-polymerized denture resin, J Prosthet Dent 74(3) : 242-249, 1995.

5) Umemoto, K. and Kurata, S.: Effects of mixed silane coupling agent on porcelain tooth material and various dental alloys, Dent Mater J 14(2): 135-142, 1995.

6) Iwamoto, K.: A study of acrylic resin bonding to porcelain - Effect of gammamethacryloxypropyltrimethoxysilane-, J Kyushu Dent Soc 39:718-741, 1985. (in Japanese)

7) Imai, M.: Pre-treatment of porcelain surface for adhesive restorations, $J J$ Dent Mater 9 (2) : 301-313, 1990. (in Japanese)

8) Kurata, S. and Yamasaki, N.: Effect of silane coupling agents with various organofunctional and hydrolysable groups on silicon and its water-resistance, $J J$ Dent Mater 11(6) : 916-921, 1992. (in Japanese)

9) Oku, J.: Impact properties of acrylic denture base resin Part 2 Effect of temperature and residual monomer on impact characteristics, Dent Mater $J$ 8(2): 186-193, 1989.

10) Fujii, K.: Fatigue properties of acrylic denture base resins, Dent Mater J 8(2): 243-259, 1989.

11) Tanioka, Y. and Nishiyama, N.: Surface treatment of silica filler influence of the number of silicone functional group in silane coupling agents on the surface treatment of silica filler, $J J$ Dent Mater 6(6) : 737-746, 1987. (in Japanese)

12) Kurata, S. and Yamasaki, N.: Effect of coupling agents of isocyanate- and alkoxysilanes and zircoaluminates on silica surface, $J J$ Dent Mater 6(5):679-684, 1987. (in Japanese)

13) Nishiyama, N.: Studies on behaviour of silane coupling agent at the interface of silica/ methacrylic resin, $J J$ Dent Mater 5(4):519-528, 1986. (in Japanese)

14) Sakanashi, K. and Nishiyama, N.: Studies on the treatment of glass surface-treatment of glass surface by $\gamma$-methacryloxy-alkyl-trimethoxysilanes with different chain lengths and its reinforcement effects-, $J J$ Dent Mater $3(2): 284-294$, 1984. (in Japanese) 